\title{
GRAFENIKA [GRAPHENICS]
}

\section{RUSSIAN GUBIN'S SEMINAR (MOSCOW)}

\section{Elena Yu. Buslaeva}

VNIIAlmaz, http://www.vniialmaz.ru, Ltd. AkKoLab, http://www.akkolab.ru

Moscow 107996, Russian Federation

Kurnakov Institute of General and Inorganic Chemistry, Russian Academy of Sciences, http://www. igic.ras.ru

Moscow 117991, Russian Federation

eyubuslaeva@inbox.ru

Russian Seminar "GRAPHENE: MOLECULE AND CRYSTAL (material, physics, chemistry, electronics, photonics, biomedical applications)" under the direction of prof. SP Gubin operates from November 2011. Seminar sessions are held once a month, mainly in the boardroom VNIIAlmaz in Gilyarovskogo str., 65 (metro station "Rizhskaya"). The seminar is supported by LLC "AkKoLab" and the VNIIAlmaz. Programms of seminars are available at http://www.akkolab.ru. The seminar organizers see it as a discussion platform to discuss new ideas and concepts, review the results and the exchange of experience of researchers in the booming grafenika - an interdisciplinary field of modern science. Anticipated publication of an annual compendium of seminar materials, creating Programs of research in this area with possible access to financing. The seminar was attended by officials from various scientific institutions of Moscow - Kurnakov Institute of General and Inorganic Chemistry RAS, Nesmeyanov Institute of Organoelement Compounds of RAS, Semenov Institute of Chemical Physics RAS, Kotel'nikov Institute of Radio Engineering and Electronics RAS, National Research Centre "Kurchatov Institute", Moscow State University Department of Chemistry, Moscow Institute of Physics and Technology, National Research Nuclear University "MEPhI", People's Friendship University of Russia, LLC "AkKoLab", Open Joint Stock Company (JSC) "VNII ALMAZ", LLC "Karbonlayt", JSC NIIgrafit and others, as well as invited members of scientific institutions in Russia, Commonwealth of Independent States (CIS) and foreign countries. The audience for each session - about fifty participants. In the four- hour meeting with a break heard and discussed the 3-4 reports, news review and submitted poster presentations.

The journal RENSIT is published semi-annual reports of this seminar: list of reports indicating affiliated authors and submitted abstracts.

PACS: $01.10 \mathrm{Fv}$

DOI: $10.17725 /$ rensit.2017.09.126

TWENTY-EIGHT SEMINAR, 15.01.2016

1. Bocharov G.S., Mel'nikov V.P., Eletskii A.V., Dr Sci Techn., Professor (MEI, Moscow). The nonlinear heat-conductivity of the recovered graphene oxide. 2. Obraztsova E.D., PhD Phys\&Math, Tonkikh A.A., TsebroV.I., Rybkowski D.V., Obraztsova E.A., Chuvilin A.L., Kauppinen E. (CENI GPI RAS) Film from the filled single-walled carbon nanotubes - a new material for optoelectronics.
3. Chervonobrodov S.P., $\mathrm{PhD}$ Phys\&Math, Moscow. On the application of nano-materials in electrochemical energy storage (according to the discussions at the expert session, held in RUSNANO 15 and 21 December 2016).

TWENTY-NINTH WORKSHOP 22.03.2017 1. Zhuravlev V.V., Dr Sci Techn (JSC VNIIALMAZ). New materials based on graphene oxide and graphene; the work of the VNIIALMAZ for 2015-2016. 
2. Burmistrov I.S., Dr Sci Phys\&Math (Landau ITP RAS). Quantum graphene elasticity: coefficient of thermal expansion and heat capacity.

\section{THIRTIETH WORKSHOP 24.05.2017}

1. Gall N.R., Dr Sci Phys\&Math, prof.; Rudikov E.V. (Ioffe FTI RAS, Saint-Petersburg). The problem of "ideality" of graphene, obtained by CVD and high temperature diffusion from the bulk.

2. Danilov E.A., Samoilov M.V., Dmitriev V.S., Nikolaeva A.B., Ponomarev D.V., Timoshchuk E.I. (JSC NIIgrafit). Obtaining a transparent conductive films based on graphene and metal nanoparticles by the method of Langmuir-Blodgett films.

3. Korolev V.V., Dr Sci Chem (Institute of solution chemistry of RAS, Ivanovo), Koksharov Yu.A., Gubin S.P. (IGIC RAS). Magnetocaloric effect in graphene.

\section{DIFFERENT.}

